\title{
VÍRUS BRASILEIROS DA FAMÍLIA BUNYAVIRIDAE
}

\author{
BRAZILIAN VIRUSES IN THE FAMILY BUNYAVIRIDAE
}

Luiz Tadeu M. Figueiredo

\begin{abstract}
Docente do Departamento de Clínica Médica da Faculdade de Medicina de Ribeirão Preto da Universidade de São Paulo. Correspondência: Prof.Dr. Luiz Tadeu M. Figueiredo. Unidade Multidepartamental de Pesquisa em Virologia da Faculdade de Medicina de Ribeirão Preto da Universidade de São Paulo - Campus Universitário - CEP: 14049-900 - Ribeirão Preto - SP - Brasil. E-mail: Itmfigue@fmrp.usp.br.
\end{abstract}

FIGUEIREDO LTM. Vírus brasileiros da família Bunyaviridae. Medicina, Ribeirão Preto, 32: 154-158, abr./jun. 1999.

RESUMO: Os vírus brasileiros da família Bunyaviridae são vírus RNA, isolados principalmente na Região Amazônica, pertecentes aos gêneros Bunyavirus, Hantavirus e Phlebovirus. A grande maioria destes vírus são transmitidos por mosquitos e flebótomos, exceto os Hantavirus que têm transmissão relacionada à inalação de aerossóis dos excretas de roedores. A estrutura, a composição e o mecanismo de replicação dos Bunyaviridae são brevemente revistos neste trabalho. Também, são analisados aspectos epidemiológicos e clínicos das doenças causadas pelos seguintes Bunyaviridae brasileiros: Oropouche, Apeú, Caraparu, Marituba, Guaroa, Tacaiuma, Guamá, Maguari, Candiru e Hantavirus.

UNITERMOS: Bunyaviridae.

A família Bunyaviridae inclui mais de trezentos (300) vírus distintos, compreendidos em quatro (4) gêneros: Bunyavirus (espécie tipo: Bunyamwera), Hantavirus (Hantaan), Nairovirus (vírus da febre hemorrágica do Congo e da Criméia) e Phlebovirus (febre dos flebótomos da Sicília $)^{(1,2)}$. Cada gênero da família Bunyaviridae inclui múltiplos sorotipos ${ }^{(3)}$. A grande maioria destes vírus são arbovírus transmitidos por mosquitos, flebótomos ou carrapatos, e mantidos na natureza como zoonoses ${ }^{(1,4)}$. Fazem exceção os Hantavirus, que infectam roedores e têm mecanismo de transmissão relacionado à inalação de aerossóis dos excretas destes animais ${ }^{(5)}$. Também pertence à família Bunyaviridae o gênero Tospovirus que inclui vírus vegetais ${ }^{(6)}$. No Brasil, foram isolados dezenas de vírus da família Bunyaviridae, sendo o mais importante deles, do ponto de vista epidemiológico, o vírus Oropouche, por causar epidemias extensas na Região Amazônica ${ }^{(7)}$.

\section{CARACTERÍSTICAS DOS VÍRUS DA FA- MÍLIA BUNYAVIRIDAE E SUA REPLICA- ÇÃ O}

Os Bunyaviridae são vírus de RNA, esféricos e envelopados, medindo de 80 a $120 \mathrm{~nm}$, que possuem projeções glicoprotéicas na superfície. Têm na composição química $2 \%$ de RNA, $58 \%$ de proteínas, $33 \%$ de lipídios, e 7\% de carboidratos (vírus Uukuniemi) ${ }^{(2,6)}$. Possuem RNA de fita, simples e trissegmentado. Dois segmentos têm polaridade negativa (RNAc) e são denominados grande (L), com seis mil, oitocentos e setenta e cinco (6875) nucleotídios (vírus Bunyamwera) e médio (M), com quatro mil, quatrocentos e cinquienta e oito (4458) nucleotídios (vírus Bunyamwera). O terceiro segmento, denominado pequeno pequeno (S), com novecentos e sessenta e um (961) nucleotídios (Bunyamwera) pode ser ambisense em alguns membros da família ${ }^{(2,8,9,10)}$. Os tamanhos 
dos três (3) segmentos variam entre os quatro (4) diferentes gêneros da família Bunyaviridae e as seqüências complementares 5' e 3' terminais oferecem ligações estáveis, não covalentes, com pareamento de bases, o que permite aos segmentos apresentarem-se em forma circular ${ }^{(6)}$. O virion carrega, também, uma polimerase (cap-dependente), de 240 a $260 \mathrm{KD}$, denominada L. As extremidades dos segmentos de RNA servem como sítio de reconhecimento para a polimerase viral ${ }^{(6)}$.

As proteínas estruturais dos vírus da família $B u$ nyaviridae são a ribonucleoproteína $\mathrm{N}$, com $26,5 \mathrm{kD}$, que é codificada no segmento $S$ do RNA viral. Também as proteínas G1 e G2, do envelope viral, são proteínas estruturais, codificadas no segmento M. A proteína L é codificada no segmento do mesmo nome. A estratégia da replicação em $\mathrm{S}$ é ambisense em vários membros da família, sendo a open reading frame da nucleoproteína $\mathrm{N}$, localizada na primeira metade do segmento, próxima à extremidade 5' e à proteína NSs, na segunda metade ${ }^{(6,11)}$. Esta proteína não estrutural NSs, com $7,4 \mathrm{kD}$, tem função pouco conhecida. A proteína não estrutural NSm, de $11 \mathrm{kD}$, presente apenas nos Bunyavirus e Phlebovirus, é codificada no segmento $M$ do RNA viral, em uma região situada entre $\mathrm{G} 2$ e $\mathrm{G} 1^{(6,12)}$.

A infecção por vírus da família Bunyaviridae inicia-se pela ligação do microorganismo à membrana celular, sendo ligantes a proteína G1 para células de vertebrados e a proteína G2 para células de artrópo$\operatorname{dos}^{(2)}$. Os vírus invadem a célula, provavelmente por endocitose, e fundem seu envelope a membranas endossômicas, o que permite ao nucleocapsídio viral atingir o citoplasma. Caracteristicamente, o genoma viral permanece como ribonucleoproteína, sem desnudamento total do capsídio, que se apresenta com formato circular, associado a numerosas cópias da proteína $\mathrm{N}$ e poucas cópias da proteína L (RNA polimerase) $)^{(6,11)}$. Primeiramente, utilizando a polimerase viral, ocorre uma transcrição primária de RNA (-) do vírus a RNA (+) mensageiro e uma replicação a RNA (+) complementar. Em seguida, em ribossomas livres, inicia-se uma rápida tradução dos RNAm dos segmentos L e S. As proteínas N e NSs de Phlebovirus estão presentes no citoplasma da célula infectada duas (2) horas após a infecção. Tradução, também, ocorre com o RNAm de M, o qual se liga a ribossomas de membrana e ali ocorre a síntese de uma poliprotéina. Em determinado momento, a polimerase viral muda sua fun- ção da transcrição primária de RNAm do genoma viral para a replicação do genoma da progênie ${ }^{(6)}$. Iniciase a transcrição do RNA (+) complementar, a partir do terminal 3', produzindo-se o RNA (-) encapsidado na progênie viral. A poliproteína codificada pelo segmento M é clivada, formando G1 e G2, as quais são, em seguida, glicosiladas. Da clivagem resultam, também, proteínas não estruturais, com 14 e $48 \mathrm{kD}$. As glicoproteínas possuem domínios através da membrana, indicando área de ancoramento em membrana, e sequiências hidrofóbicas e carboxi-terminais ${ }^{(6)}$. A montagem viral ocorre após acúmulo de G1 e G2 junto ao aparelho de Golgi e, em seguida, a partícula viral brota neste aparelho. Finalmente, a progênie viral é liberada por pinocitose reversa com fusão das membranas das vesículas citoplasmáticas à membrana celular ${ }^{(6)}$.

\section{ASPECTOS DA EPIDEMIOLOGIA E DAS DOENÇAS CAUSADAS POR VÍRUS DA FAMÍLIA BUNYAVIRIDAE}

Os vírus da família Bunyaviridae são reconhecidos por causarem doenças humanas graves e freqüentemente fatais, o que ocorre, por exemplo, nas infecções pelo vírus da febre do Vale Rift, pelo vírus da febre hemorrágica do Congo e da Criméia e pelo vírus La Crosse da encefalite da Califórnia ${ }^{(2,13)}$. No Brasil, diversos membros desta família produzem doença humana. O Bunyavirus Oropouche, do grupo sorológico Simbu, é um dos arbovírus de maior importância epidemiológica, apenas superado pelo dengue em número de casos notificados ${ }^{(7,14 / 18)}$. O vírus também circula em países vizinhos ${ }^{(19)}$. Este vírus é causador de extensas e explosivas epidemias de doença febril aguda em cidades e vilarejos da Região Amazônica e do Planalto Central, com grande impacto econômico e social ${ }^{(7,17,18,20,21)}$. Em curto espaço de tempo, milhares de indivíduos adoecem. A febre do Oropouche tem início abrupto. Febre, cefaléia, mialgias, artralgias, anorexia, tonturas, calafrios e fotofobia são os sintomas habituais desta doença. Descreve-se, em $5 \%$ dos casos, exantema morbiliforme que lembra o da rubéola e são descritos casos com náuseas, vômitos, diarréia, congestão conjuntival, dor epigástrica e dor retroocular. Em um número menor de pacientes, o Oropouche pode infectar o sistema nervoso central, produzindo meningite linfomonocitária, que tem evolução benigna ${ }^{(7,17,18)}$. Esta virose mantém-se na natureza através de dois ciclos, um urbano e outro silvestre. O ciclo silvestre envolve, como reservatórios, noventa e cinco (95) espécies de aves silvestres, maca- 
cos e preguiças (estes animais comumente apresentam anticorpos para o vírus). Suspeita-se que o mosquito Aedes serratus possa ser o vetor silvestre do vírus Oropouche. Quanto ao ciclo urbano, relacionado às epidemias, costuma ocorrer nas estações chuvosas, tem o homem como reservatório e o mosquito, Culicoides paraensis (maruim), como vetor ${ }^{(7,17,22)}$. São criadouros do maruim os acúmulos de água nas cascas de cacau ou troncos de bananeira. No combate às epidemias de Oropouche, devem-se utilizar inseticidas para eliminar a fase larvária do vetor em seus criadouros $^{(23)}$. Na década de oitenta (80), em um inquérito sorológico para arbovírus, na região de Ribeirão Preto, observaram-se dois moradores urbanos, ambos naturais do Estado de Minas Gerais, com anticorpos inibidores da hemaglutinação para Oropouche (positividade $<1 \%)^{(24)}$. Pertence, também, ao grupo sorológico Simbu o vírus Jatobal, que foi isolado do sangue de um Nasua nasua (quati) capturado em Tucuruí, Estado do Pará, em 1984(25).

Os Bunyavirus do grupo sorológico $\mathrm{C}$ incluem os vírus Apeú, Caraparu e Marituba ${ }^{(1)}$. Todos estes vírus foram isolados, na Região Amazônica, de seres humanos, portando doenças febris agudas. A febre do Caraparu, tem duração de quatro (4) a cinco (5) dias e caracteriza-se por febre, cefaléia, calafrios, mialgias, fotofobia e dor retrobulbar. Acredita-se que mosquitos Culicidae sejam os vetores destes vírus, e roedores os seus reservatórios ${ }^{(7)}$. No Estado de São Paulo, o vírus Caraparu circula na região de Mata Atlântica, causando infecções e doença febril aguda em moradores e visitantes da região do Vale do Ribei$\mathrm{ra}^{(26)}$. Nessa região, o vírus foi isolado do mosquito Culex (Mel.) sacchettae, em 1976, e têm sido encontrados roedores, Coendou milanurus, Akodon, Nectomys, Oryzomys e Oxymecterus, bem como marsupiais, Didelphis marsupialis, com anticorpos antica$\operatorname{raparu}^{(26)}$.

O Bunyavirus Guaroa, pertence ao sorogrupo Califórnia ${ }^{(26,27)}$. Pelo menos onze isolamentos deste vírus foram obtidos de seres humanos, na Região Amazônica. Originalmente encontrado na Colômbia, foi isolado, pela primeira vez no Brasil, a partir da biópsia de fígado de uma paciente que apresentava hepatopatia, paralisia e queda de cabelos ${ }^{(28)}$. Os outros casos apresentavam doença febril aguda ${ }^{(7)}$. Na década de oitenta (80), em inquérito sorológico para arbovírus, na região de Ribeirão Preto, observou-se um morador de zona rural com anticorpos inibidores da hemaglutinação para Guaroa (positividade $<0,5 \%)^{(24)}$.
O Bunyavirus Tacaiuma, pertencente ao grupo sorológico Anopheles A, foi isolado de seres humanos, macacos, animais sentinela e mosquitos Haemagogos $s p$ e Aedes triannulatus ${ }^{(1,7,27)}$. Estes artrópodos são considerados os vetores do vírus Tacaiuma na Região Amazônica. No Estado de São Paulo, este vírus já foi isolado de um mosquito Anopheles cruzii e de um paciente apresentando quadro febril ${ }^{(26)}$. $\mathrm{Na}$ década de oitenta (80), em inquérito sorológico para arbovírus, na região de Ribeirão Preto, observou-se um morador de zona rural com anticorpos inibidores da hemaglutinação para Tacaiuma (positividade $<0,5 \%)^{(24)}$. Ainda, cavalos, apresentando anticorpos para Tacaiuma, foram descritos na Região do Pantanal ${ }^{(29)}$.

O Bunyavirus Guamá, pertencente a sorogrupo com o mesmo nome, foi isolado do sangue de nove (9) indivíduos da Região Amazônica, apresentando doença com início súbito, caracterizada por febre moderada, tonturas, cefaléia, mialgias, artralgias e fotofobia ${ }^{(7,27)}$. Acredita-se que o ciclo silvático deste vírus envolva Culex $s p$ como vetores e vários roedores como reservatórios. O Bunyavirus Cananéia pertence também ao sorogrupo Guamá. Foi isolado de culicídios e animais sentinela no litoral sul do Estado de São Paulo ${ }^{(1)}$.

O Bunyavirus Maguari pertence ao sorogrupo Bunyamwera, tem hospedeiros de hábitos diurnos (Aedes scapularis, Aedes serratus, Aedes fulvus e Psorophora ferox) e de hábitos noturnos (Anopheles nuneztovari e Anopheles triannulatus) ${ }^{(7)}$. Cavalos apresentando anticorpos para Maguari foram descritos na Região do Pantanal ${ }^{(29)}$. O Bunyavirus Sororoca, do mesmo sorogrupo, foi isolado de mosquito Sabethini, na Amazônia ${ }^{(30)}$.

O Bunyavirus Capim pertence a sorogrupo com este nome, tendo sido isolado de mosquitos culicídios e de animais sentinela, na Região Amazônica ${ }^{(7,27)}$. $\mathrm{O}$ vírus Guajará, pertencente ao mesmo sorogrupo, foi isolado de mosquitos culicídios e de roedores, na Região Amazônica ${ }^{(7,27)}$.

Dentre os Bunyaviridae do gênero Phlebovirus, o vírus Candiru, que pertence ao sorogrupo do mesmo nome, foi isolado de seres humanos da Região Amazônica com doença autolimitada, flu-like, com duração de um (1) a cinco (5) dias, caracterizada por início súbito, com febre alta, cefaléia frontal, lombalgia e mialgias generalizadas, fotofobia e dor retroauricu$\operatorname{lar}^{(7,27)}$. Este vírus é transmitido por flebotomíneos do gênero Lutzomyia e tem animal reservatório desconhecido $^{(7)}$. 
Os Hantavirus são importantes causadores de graves doenças humanas ${ }^{(2,5,31)}$. São vírus de roedores, que, na Ásia e Europa, causam febre hemorrágica com síndrome renal ${ }^{(32)}$, e, nas Américas, síndrome pulmonar ${ }^{(33)}$. Esta síndrome caracteriza-se por extravasamento de líquidos do compartimento intravascular para o interstício pulmonar, causando edema com aumento da barreira alveolocapilar, podendo levar a grave insuficiência respiratória. Os Hantavirus americanos têm sua evolução em íntimo relacionamento com a evolução de seus animais reservatório, os quais são Rodentia, Muridae da subfamília Sigmodontinae ${ }^{(34)}$. Um Hantavirus foi isolado no Brasil, pela primeira vez, no Pará, de um Rattus norvegicus, na década de oitenta $(80)^{(35)}$. Também, demonstrou-se presença de anticorpos para Hantaan em soros de ratos de Belém, São Paulo e Recife ${ }^{(32)}$. Numa série com duzentos e doze (212) soros de pacientes da Região Norte do Brasil, com suspeita de leptospirose, encontrou-se IgG para Hantaan em 8,4\% e IgM em $1,9 \%{ }^{(32)}$. Em São Paulo, em 1976, cinco (5) de quatrocentos e nove (409) doentes internados com diagnóstico clínico de leptospirose apresentavam IgM para Hantaan ${ }^{(32)}$.

Em 1993, entre novembro e dezembro, adoeceram três (3) indivíduos moradores da área rural de Juquitiba, SP. Os doentes apresentaram febre, cefaléia, prostração, náuseas e vômitos. Dois pacientes evoluiram com insuficiência respiratória aguda. Um paciente entrou em choque e morreu. O diagnóstico sorológico destes casos confirmou infecção recente por Hantavirus, evidenciando a ocorrência de hantavirose com síndrome pulmonar, no Brasil ${ }^{(32)}$. Em abril de 1998, dois (2) outros casos de hantavirose, um cur- sando com síndrome pulmonar e outro com hemorragias, ocorreram no oeste do Estado de São Paulo, nos Municípios de Tupi Paulista e Nova Guataporanga. Finalmente, dois (2) casos de síndrome pulmonar fatal por hantavirose ocorreram em maio de 1998, no Município de Guariba, SP, situado a $40 \mathrm{Km}$ de Ribeirão Preto. Os pacientes tinham atividade ligada ao meio rural e tinham contato com milho armazenado em paiol infestado por roedores. Estes pacientes, após dois (2) ou três (3) dias de quadro febril inespecífico, evoluiram com grave pneumonia intersticial, acometendo extensamente ambos os pulmões e levando a insuficiência respiratória com conseqüente óbito. A confirmação etiológica destes dois (2) últimos casos foi feita pela amplificação de parte do genoma viral através da reação em cadeia da polimerase, precedida de uma transcrição reversa (RT-PCR) utilizando iniciadores (primers) específicos para Hantavirus e, também, pela detecção por ensaio imunoenzimático de anticorpos IgM contra o Hantavirus Andes.

Em uma epidemia, na Região de Bariloche, Sul da Argentina, o Hantavirus Andes, foi isolado do tecido pulmonar de uma paciente. Ocorreram casos de síndrome pulmonar, acometendo vinte (20) indivíduos, entre setembro e dezembro de 1996. Cinco pacientes eram médicos, outros eram funcionários de hospital, inclusive alguns destes infectaram-se por contato com pacientes fora da área, em Buenos Aires. Observou-se, naquele surto, a transmissão interpessoal do vírus, por contato direto, aerossóis ou fômites contaminados. Tal tipo de transmissão, ainda desconhecido para Hantavirus, não foi observado em outros surtos ocorridos nas Américas ${ }^{(36)}$.

FIGUEIREDO LTM. Brazilian viruses in the family Bunyaviridae. Medicina, Ribeirão Preto, 32: 154-158, apr./june 1999.

SUMmARY: The Brazilian Bunyaviridae are RNA viruses belonging to the Bunyavirus, Hantavirus, and Phlebovirus genera isolated mainly in the Amazon region. These viruses are transmitted by mosquitoes and phlebotomus, with the exception of those in the Hantavirus genus which are transmitted by inhalation of aerosos of rodent excreta. Most of the Brazilian Bunyaviridae were isolated in the Amazon region. The structure, composition, and replication mechanism of the Bunyaviridae are described, as well as the epidemiology and clinical manifestations of the diseases caused by the following viruses: Oropouche, Apeú, Caraparu, Marituba, Guaroa, Tacaiuma, Guamá, Maguari, Candiru, and Hantavirus.

UNITERMS: Bunyaviridae. 


\section{REFERÊNCIAS BIBLIOGRÁFICAS}

1 - KARABATSOS N. International catalogue of arboviruses including certain other viruses of vertebrates, 3th ed., American Society of Tropical Medicine and Hygiene, San Antonio, 1985.

2 - MERTZ GJ. Bunyaviridae: bunyaviruruses, phleboviruses, nairoviruses, and hantaviruses. In: RICHMAN DD; WHITLEY RJ \& HAYDEN FG, eds. Clinical virology, Churchill-Livingstone, New York, p. 943-972, 1997.

3 - HUNT AR \& CALISHER CH. Relationships of Bunyamwera group viruses by neutralization. Am J Trop Med Hyg 28: 740-749, 1979

4 - DÉGALLIER $\mathrm{N}$ et al. Modifications of arbovirus eco-epidemiology in Tucurui, Para, Brazil, related to the construction of a hydroeletric dam. In: Proceedings, V Symposium on Arbovirus Research in Australia. Brisbane, p. 124-135, 1989.

5 - SCHMALJOHN CS \& HJELLE B. Hantaviruses: a global disease problem. Emerg Infect Dis 3: 95-104, 1997.

6 - SCHMALJOHN CS. Bunyaviridae: the viruses and their replication. In: FIELDS B; KNIPE DM \& HOWLEY, eds. Fundamental virology, Lipincott-Raven, Philadelphia, p. 649-673, 1996.

7 - VASCONCELOS PF et al. Clinical and ecoepidemiological situation of human arboviruses in Brazilian Amazonia. Ciênc Cult 44: 117- 124, 1992.

8 - ELLIOTT RM. Nucleotide sequence analysis of the large (L) genomic RNA segment of Bunyamwera virus, the prototype of the family Bunyaviridae. Virology 173: 426-436,1989.

9 - ELLIOTT RM. Nucleotide sequence analysis of the small (S) RNA segment of Bunyamwera virus, the prototype of the family Bunyaviridae. J Gen Virol 70: 1280-1285, 1989.

10 - LEES JF et al. Nucleotide sequence of the Bunyamwera virus $M$ RNA segment: Conservation of structural features in the Bunyavirus glycoprotein gene product. Virology 148: $1-14,1986$.

11 - ROBERTS A et al. Completion of the La Crosse virus genome sequence and genetic comparisons of the $L$ proteins of the Bunyaviridae. Virology 206: 742-745,1995.

12 - PEKOSZ A \& GONZÁLEZ-SCARANO F. The extracellular domain of $L a$ Crosse virus $G 1$ forms oligomers and undergoes $\mathrm{pH}$-dependent conformational changes. Virology 225: 243-247, 1996

13 - MANGIAFICO JA et al. Isolation of a newly recognized Bunyamwera serogroup virus from a febrile human in Panama. Am J Trop Med Hyg 39: 593-596, 1988

14 - DIXON KE et al. Oropouche virus: Epidemiological observations during na epidemic in Santarém, Pará, Brazil in 1975. Am J Trop Med Hyg 30: 161-164, 1981.

15 - FIGUEIREDO LTM. Palestra: Os arbovírus do Brasil. In: Anais, II Reunião Anual da Sociedade Brasileira de Pesquisadores Nikkeis, Sessão III- Virologia, São Paulo, p. 45-58, 1994.

16 - KINNEY RM \& CALISHER CH. Antigenic relationships among Simbu serogroup (Bunyaviridae) viruses. Am J Trop Med Hyg 30: 1307-1318, 1981.

17 - PINHEIRO FP et al. Oropouche virus I. A review of clinical, epidemiological, and ecological findings. Am J Trop Med Hyg 30: 149-160, 1981.
18 - PINHEIRO FP et al. Meningite associada às infecções por vírus Oropouche. Rev Inst Med Trop São Paulo 24: 246-251, 1982.

19 - WATTS DM et al. VEE and Oropouche virus infections among Peruvian army troops in the Amazon Region of Peru. Am J Trop Med Hyg 56: 661-667, 1997.

20 - FREITAS RB et al. Epidemia de vírus Oropouche no Leste do Estado do Pará, 1979. Rev FSESP 25: 59-72, 1980.

21 - VASCONCELOS PFC et al. Primeiro registro de epidemias causadas pelo vírus Oropouche nos Estados do Maranhão e Goiás, Brasil. Rev Inst Med Trop São Paulo 31: 271-278, 1989.

22 - ROBERTS DR et al. Oropouche virus: Entomological observations from three epidemics in Pará, Brazil, 1975. Am J Trop Med Hyg 30: 165-171, 1981.

23 - PINHEIRO FP et al. Febre por Oropouche. In: LEÃO RNQ, ed. Doenças infecciosas e parasitárias - Enfoque Amazônico, CEJUP, Belém, p. 285-298, 1997.

24 - FIGUEIREDO LTM et al. Níveis de anticorpos para arbovírus em indivíduos da Região de Ribeirão Preto, SP (Brasil). Rev Saúde Pública São Paulo 20: 204-211, 1986

25 - FIGUEIREDO LTM \& TRAVASSOS DA ROSAA. Jatobal virus antigenic characterization by ELISA and neutralization test using EIA as indicator, on tissue culture. Mem Inst Oswaldo Cruz 83: 161-164, 1987.

26 - IVERSSON LB. Situação atual do conhecimento eco-epidemiológico, sobre arbovirus patogênicos para o homem na Região da Mata Atlântica do Estado de São Paulo. Rev Inst Med Trop São Paulo 36: 343-353, 1994.

27 - PINHEIRO FP. Situação das arboviroses na região Amazônica. Anais, Simpósio Internacional sobre Arbovírus dos Trópicos e Febres Hemorrágicas, Academia Brasileira de Ciências, Belém, p. 27-48, 1985.

28 - CAUSEY OR et al. Isolamento do vírus Guaroa do fígado por biópsia percutânea de um caso humano com paralisia. Rev SESP 12: 55-59, 1962.

29 - IVERSSON LB et al. Circulation of EEE, WEE, Ilhéus, Maguari and Tacaiuma viruses in equines of the Brazilian Pantanal, South America. Rev Inst Med Trop São Paulo 35: 355359, 1993.

30 - SHOPE RE et al. Itaqui virus, a new member of arthropodborne group C. Am J Trop Med Hyg 10: 264-265, 1961.

31 - ZHAO X \& HAY J. The evolution of Hantaviruses. Immunol Invest 26: 191-197, 1997.

32 - IVERSSON L. Doença humana por hantavirus. In: VERONESI $R$ \& FOCACCIA R, eds. Tratado de infectologia, Atheneu, São Paulo, p. 219-228, 1996.

33 - DULL SM et al. Hantavirus Pulmonary Syndrome: recognition and emergency department management. Ann Emerg Med 24: 530-536, 1994.

34 - XIAO SY et al. Phylogenetic analyses of virus isolates in the genus Hantavirus, Family Bunyaviridae. Virology 198: 205-217, 1994.

35 - LEDUC JW et al. Isolation of a Hantaan-related virus from Brazilian rats and serologic evidence of its widespread distribution in South America. Am J Trop Med Hyg 34: 810-815, 1985.

36 - WELLS RM et al. An unusual Hantavirus outbreak in Southern Argentina: person-to-person transmission? Emerg Infect Dis 3: 171-174, 1997.

Recebido para publicação em 05/05/99

Aprovado para publicação em 02/06/99 